\title{
Conflitos no Processo de Constituição e Regularização do Parque Nacional do Iguaçu - PR
}

\author{
Conflicts in the Process of Constitution and Regularization of Iguazu National \\ Park - PR \\ Conflictos en el Proceso de Constitución y Regularización del Parque Nacional del \\ Iguazu - PR
}

Edson dos Santos Dias ${ }^{1}$

\begin{abstract}
RESUMO: No presente artigo o objetivo é analisar a problemática associada à regularização fundiária de áreas protegidas, tendo como estudo de caso a situação do Parque Nacional do Iguaçu (PNI). As adversidades para a regularização fundiária representam um grave problema que acompanha a criação das unidades de conservação por todo o país e que, não raro, permanece sem solução por décadas. Para além das dificuldades orçamentárias para a regularização das áreas protegidas brasileiras, o que é um problema crônico, a questão torna-se mais complexa quando essas áreas - no caso da categoria de proteção integral - apresentam ocupação humana. O estudo apresenta, na primeira parte do artigo, os problemas relacionados ao financiamento da regularização das áreas protegidas. Na segunda parte, o intuito é discorrer sobre a importância do PNI no conjunto paranaense de áreas protegidas. Por último, é analisado o processo de regularização fundiária do $\mathrm{PNI}$ e os seus conflitos.
\end{abstract}

PALAVRAS-CHAVE: Regularização fundiária. Conflitos. Unidades de conservação.

ABSTRACT: The objective of this article is to analyze from problems associated with the land regularization of protected areas, having as case study the situation of the lguazu National Park (INP). The adversities of land regularization represent a serious issue that accompanies the creation of conservation units throughout the country and which, not rarely, remains unsolved for decades. In addition to the budget difficulties, the regularization of Brazilian protected areas, which is a chronic problem, the issue becomes more complex when these areas, in the case of the category of full protection, present human occupation. The study presents in the first part of the paper the complications related to the financing of the regularization of protected areas. In the second part, the purpose is to discuss the importance of the INP along the protected areas of Parana state. Finally, this study analyzed the process of land regularization of the INP and its conflicts.

KEYWORDS: Land regularization. Conflicts. Conservation units.

RESUMEN: En el presente artículo el objetivo es analizar la problemática asociada a la regularización agraria de áreas protegidas, teniendo como estudio de caso la situación del Parque Nacional del Iguazú (PNI). Las adversidades para la regularización agraria representan un grave problema que acompaña la creación de las unidades de conservación por todo el país y que, no raramente, permanece sin solución por décadas. Además de las dificultades presupuestarias para la regularización de las áreas protegidas brasileñas, lo que es un problema crónico, el dilema se vuelve más complejo cuando esas áreas - en el caso de la categoría de protección integral - presentan ocupación humana. El estudio presenta en la primera parte del artículo los problemas relacionados con la financiación de la regularización de las áreas protegidas. En la segunda parte, la intención es discurrir sobre la importancia del PNI en el conjunto paranaense de áreas protegidas. Por último, se analiza el proceso de regularización agraria del PNI y sus conflictos.

PALABRAS CLAVES: Regularización agraria. Conflictos. Unidades de conservación.

\footnotetext{
${ }^{1}$ UNIOESTE/ M. C. Rondon. Endereço: R. Graciliano Ramos, 54 Lot. Avenidas M. C. Rondon - PR CEP 85.960-000; edsondias87@yahoo.com.br.
} 


\section{INTRODUÇÃO}

Em nosso país, para preservar parte da área de floresta remanescente são utilizados instrumentos de regulação fiscal (incentivo através do ICMS Ecológico que, no caso do Paraná, encontra-se vigente desde 1991) e jurídica - reserva legal; área de preservação permanente (APP) e criação de unidades de conservação da natureza, divididas nas modalidades de proteção integral e de uso sustentável.

As unidades de conservação são implantadas em um contexto permeado por conflitos, contradições, resistências e busca de mediações e diálogo, com repercussão entre grupos ou agentes sociais tão distintos como latifundiários, pequenos agricultores, populações tradicionais e ONGs ambientalistas nacionais e internacionais. Nesse contexto, o Estado possui papel fundamental como agente promotor e executor da implantação das áreas protegidas, o que não significa ignorar possíveis posicionamentos divergentes dentro do próprio Estado - entre os órgãos governamentais. Há diversos exemplos pelo país, como as divergências entre a FUNAI, o INCRA, o IBAMA e o ICMBIO que podem se mostrar mais favoráveis ou resistentes diante da criação de áreas protegidas, conforme as especificidades que envolvam a sobreposição de unidades de conservação e terras indígenas, ou terras quilombolas, ou para colonização e reforma agrária, entre outras situações.

É de amplo conhecimento as dificuldades enfrentadas para a criação, manutenção e melhoria das áreas protegidas. Entre as adversidades merece ênfase a resistência à criação de unidades de conservação, especialmente às de proteção integral. Para exemplificar essa situação no Sul do Brasil, é possível mencionar a tentativa relativamente recente de criação de unidades de conservação para proteger os remanescentes da Floresta Ombrófila Mista (Floresta com Araucárias) e a resistência por parte de setores ligados à agricultura, à pecuária e à silvicultura.

Áreas legalmente protegidas como Unidades de Conservação na Floresta com Araucárias perfazem cerca de $0,6 \%$ da área original. Os remanescentes são tipicamente pequenos, isolados e altamente alterados. [...] Contudo, a discussão pública referente às ações de conservação pretendidas gerou uma forte resistência, em boa parte pela desconfiança e carência de legitimidade das ações governamentais. Infelizmente, tanto agentes públicos quanto parcelas significativas da população ainda 
apresentam uma percepção muito negativa das florestas naturais, identificando-as como barreiras ao desenvolvimento (MEDEIROS e SAVI, 2005, p. 4).

Há ainda diversos outros problemas, como falta de planos de manejo; crônica insuficiência de pessoal responsável pelas atividades fins; conflitos com populações residentes dentro da unidade ou no seu entorno e falta de regularização fundiária das áreas protegidas, entre outras. Inclusive, as dificuldades inerentes à implementação de áreas protegidas no Brasil disseminou a expressão "parques de papel" para se referir à institucionalização da unidade de conservação através de instrumento legal, mas que não garante, de fato, a efetividade dos objetivos para a qual foi criada.

Desse conjunto de problemas, nosso objetivo é destacar a questão associada a dificuldade para a regularização fundiária das áreas protegidas brasileiras, apresentando como caso concreto o Parque Nacional do Iguaçu (PNI), frequentemente divulgado como unidade de conservação modelo diante da realidade brasileira.

\section{A DIFICULDADE ASSOCIADA AO FINANCIAMENTO DA REGULARIZAÇÃO FUNDIÁRIA DAS UNIDADES DE CONSERVAÇÃO}

Para exemplificar como a dificuldade de regularização é um problema antigo e generalizado, é emblemática a situação do Parque Nacional de Itatiaia, o primeiro parque nacional criado no país, em 1937, com área distribuída por municípios do Rio de Janeiro e Minas Gerais e que, até junho de 2016, contava com somente $51 \%$ de sua área regularizada (ICMBIO, 2016).

A falta de regularização fundiária de diversas unidades de conservação pelo país é consequência direta da falta de recursos financeiros destinados para a implementação e gestão das áreas protegidas. A insuficiência de repasse de recursos é um problema crônico que se agravou mais ainda nas últimas décadas, com a aprovação de novas áreas para compor o Sistema Nacional de Unidades de Conservação da Natureza (SNUC) que não foi acompanhada do repasse correspondente para a garantia da manutenção dessas áreas.

Pádua, ao fazer uma avaliação desse problema no Brasil, no final dos anos de 1990, escreve que: "Estima-se que cerca de $57 \%$ da somatória total de unidades de conservação, a nível federal, carecem de regularização fundiária e que para isso seriam necessários recursos da ordem de 1,8 bilhões de dólares [...]" (PÁDUA, 1997, p. 225). Informações divulgadas por Medeiros e Young (2011, p. 16 e 17), sobre o orçamento da União destinado para as unidades de conservação até o ano de 2008, indicam: 
[...] o orçamento federal para as unidades de conservação é praticamente 0 mesmo desde o ano 2000 (cerca de $\mathrm{R} \$ 300$ milhões/ano), observando um aumento de apenas $6,83 \%$ entre os anos de 2000 e 2008, enquanto no mesmo período a área somada das UCs federais teve uma expansão de $78,46 \%$. [...] o MMA aparece atrás de dezessete outros ministérios, não dispondo de recursos condizentes com a importância estratégica obtida pelo setor em nível mundial. No ano de 2009, o orçamento aprovado pelo congresso e sancionado pela Presidência da República previu uma dotação inicial para o MMA de $R \$ 3,532$ bilhões, praticamente o mesmo valor designado para a Câmara dos Deputados e quase metade daquele aprovado para as despesas da Presidência da República. Com uma diferença importante: enquanto a Câmara dos Deputados conseguiu executar praticamente todo esse orçamento e a Presidência da República teve uma suplementação de recursos de cerca de $20 \%$, o MMA executou menos da metade dos recursos destinados em função de contingenciamento.

Ainda conforme informações disponíveis no relatório citado anteriormente pode-se concluir que o investimento por hectare de unidade de conservação no Brasil, quando comparado com outros países, encontra-se desfavorável. Enquanto no Brasil se investe na manutenção do sistema de áreas protegidas, em valores aproximados, USD 4,43 por hectare, na Argentina são USD 21,37; na Costa Rica USD 32,29; no México USD 39,71; no Canadá USD 53,33; na Austrália USD 55,10; na África do Sul USD 67,09; na Nova Zelândia USD 110,39 e nos Estados Unidos USD 156,12 (MEDEIROS e YOUNG, 2011).

Mais recentemente, na atual conjuntura econômica e política brasileira a situação agravou-se, em um contexto de aprovação pelo Congresso Nacional de emenda constitucional que estabeleceu teto para os gastos públicos a partir de 2018. Conforme levantamento feito pelo WWF-Brasil (2017), em parceria com a ONG Contas Abertas, as ações orçamentárias que tratam de criação, implantação, monitoramento e projetos de manejo nas áreas protegidas têm reservado no Projeto de Lei do Orçamento de 2018 R\$ 122,9 milhões, contra uma previsão de gastos de $\mathrm{R} \$ 244,5$ milhões na proposta de 2017 , ou seja, o governo de Michel Temer (2016-2018) propôs o corte pela metade das verbas destinadas às UCs no projeto de lei orçamentária encaminhado ao Congresso.

Com a promulgação da Lei 9.985/2000, que instituiu o Sistema Nacional de Unidades de Conservação da Natureza (SNUC), buscou-se uma definição mais objetiva para o aporte de recursos destinados às unidades de conservação. De acordo com os instrumentos legais em vigor no país, uma unidade de conservação possui a seguinte definição: "[...] espaço territorial e seus recursos ambientais, incluindo as águas jurisdicionais, com características naturais relevantes, legalmente instituído pelo Poder Público, com objetivos de conservação e limites definidos, sob regime especial de administração, ao qual se aplicam garantias adequadas de proteção." (BRASIL, Lei do SNUC, 2000, p. 9).

Em 1959, a UICN procedeu a um levantamento das diversas modalidades de áreas estabelecidas em nível mundial e os dados demonstraram a existência de 115 diferentes 
tipos de áreas, tornando difícil comparar os seus objetivos e, por isso mesmo, impossível avaliar a sua efetividade (MILLER, 1997).

A necessidade de composição de um sistema de áreas naturais protegidas, se possível em escala nacional (ou mesmo internacional), no qual as diferentes modalidades interagiriam como um conjunto é defendida pelos pesquisadores e responsáveis pela administração de áreas protegidas. Trata-se de uma tentativa de romper com a prática de composição de áreas naturais conservadas de forma isolada, o que contradiz a própria dinâmica ecossistêmica. Compor esse sistema não é tarefa fácil, especialmente para um país com a grande extensão territorial do Brasil.

Em 1978, a UICN divulgou algumas diretrizes para o estabelecimento de sistemas de unidades de conservação, influenciando o IBDF (Instituto Brasileiro de Desenvolvimento Florestal) a propor um sistema de unidades de conservação para o Brasil, baseado em diversas etapas.

As iniciativas de constituição da lei do SNUC datam do ano de 1988, quando a Fundação Pró-Natureza (FUNATRA) elaborou uma primeira proposta de Projeto de Lei encomendada pelo antigo IBDF. Após vários anos de tramitação no Congresso Nacional, no início de 1998 diversas ONGs ambientalistas mobilizaram-se pela aprovação do projeto de lei, destacando-se a atuação do Fundo Mundial para a Preservação da Natureza (WWF), o Instituto Socioambiental (ISA) e o Instituto de Estudos Sócio Econômicos (INESC) (FERREIRA, 2004).

Ao final, essa lei federal foi sancionada pelo Presidente da República em julho de 2000, instituindo o Sistema Nacional de Unidades de Conservação da Natureza (SNUC), contemplando as áreas protegidas criadas sob legislação federal, estadual ou municipal. Trata-se do principal dispositivo legal voltado para a formalização de diferentes modalidades de unidades que poderiam vir a compor um sistema nacional. A aprovação dessa lei representou um avanço dentro do marco jurídico que dispõe sobre as áreas de proteção ambiental no país, em especial por uniformizar legalmente a regulação das diversas modalidades de unidades de conservação que antes se encontravam dispersas em várias leis. Procurava-se, ainda, evitar a multiplicação desordenada e sem objetivos claramente definidos de modalidades de unidades de conservação criadas pela União, estados e municípios. Qualquer proposta de implementação de uma política nacional para as áreas protegidas exige o conhecimento da situação dessas áreas (quantitativa e qualitativamente), assim como a identificação dos motivos e critérios que levaram à sua conservação.

Na lei do SNUC está prevista a manutenção de diversas categorias de manejo, o que permite uma flexibilidade maior quanto aos objetivos e tipos de uso das áreas protegidas, iniciativa indispensável para um país com grande dimensão territorial e diversidade socioespacial, como é o caso do Brasil. 
Conflitos no Processo de Constituição e Regularização do Parque Nacional do Iguaçu - PR

As unidades de conservação integrantes do SNUC (BRASIL, 2000) foram divididas em dois grupos:

- Unidades de Proteção Integral (ou de uso indireto) - têm como objetivo preservar a natureza e admitem apenas o uso indireto dos seus recursos naturais - é previsto a visitação, contemplação, estudo, educação ambiental, lazer e prática de esportes.

- Unidades de Uso Sustentável (ou de uso direto) - objetivam compatibilizar a conservação da natureza com o uso sustentável de parcela dos seus recursos naturais - permite o extrativismo, manejo ambiental, ordenamento territorial e coleta.

Ainda conforme a Lei 9.985/2000 - SNUC, em sua proposição original, no artigo 35, os recursos obtidos pelas unidades de conservação do grupo de Proteção Integral, mediante cobrança de taxa de visitação ou outras fontes de arrecadação, seriam destinados para a manutenção das unidades, inclusive para a regularização fundiária. No entanto, é preciso constar que não há garantia que o valor arrecadado seja integralmente destinado à própria unidade de conservação, pois o MMA tem a prerrogativa de remanejar esses recursos.

Segundo um ex-chefe do PNI, ao abordar o problema da insuficiência de recursos financeiros para as unidades de conservação, no ano de 2000 o referido parque recebeu mais de 800.000 visitantes, o que permitiu a arrecadação de $R \$ 4.500 .000,00$. O problema é que esse montante foi para o Tesouro, e ao PNI foi repassado, naquele ano, pouco mais de $\mathrm{R} \$ 1.400 .000,00$ (GONCHOROSKY, 20018).

A Lei do SNUC também prevê que grandes obras causadoras de danos ambientais devem destinar uma porcentagem dos custos totais contemplados para a implantação do empreendimento, exclusivamente para apoiar a criação e manutenção de unidades de conservação do grupo de proteção integral. Posteriormente, foi publicada a Regulamentação (BRASIL, Decreto nํ 4.340, de 2002) da Lei antes citada. Por essa regulamentação, em seu artigo 33, a aplicação dos recursos de compensação ambiental deve se destinar prioritariamente para a regularização fundiária e demarcação das terras das unidades de conservação.

Não obstante essa legislação constituir-se em um avanço, a efetiva cobrança desse tipo de compensação tem encontrado muitas dificuldades para estabelecer-se como instrumento normativo eficiente. Esse contexto é decorrente da resistência por parte das empresas responsáveis pela construção das grandes obras em assumir esse tipo de custo, aproveitando-se de interpretações jurídicas que lançam incertezas quanto à aplicação da Lei, marcada por conflitos de competência e judicialização excessiva (GODOY e LEUZINGER, 2015).

Dados divulgados no ano de 2005 (IBAMA, 2005) permitem conhecer o montante da arrecadação de recursos oriundos da compensação ambiental, que chegou a $R \$ 235,7$ 
milhões, cobrados no licenciamento de hidrelétricas, rodovias, gasodutos e ferrovias, entre outras obras de significativo impacto sobre a natureza. Desse total de recursos, $R \$ 16,2$ milhões foram efetivamente investidos na criação e melhoramento das unidades de conservação e $\mathrm{R} \$ 109,8$ milhões tinham cronograma de execução para 2005 e para os próximos anos. Estava previsto, ainda, que o maior volume de recursos seria destinado para a regularização fundiária $(70,7 \%)$ e o restante seria aplicado na elaboração de planos de manejo (6,3\%), implementação de unidades já criadas $(22,8 \%)$ e estudos de criação de novas unidades $(0,2 \%)$.

Apesar de discorrermos, até o momento, sobre as dificuldades de ordem orçamentária envolvidas com o processo de regularização e manutenção das áreas protegidas distribuídas pelo país, é preciso ressaltar que a questão é mais complexa e abrangente que somente a indenização. A retirada de pessoas de uma área destinada à proteção natural envolve o cotidiano, as perspectivas de futuro e as condições de vida e trabalho de diversas famílias deslocadas, conforme o direcionamento e os desdobramentos resultantes das escolhas tomadas pelos órgãos de Estado responsáveis pelo processo de regularização da área protegida na modalidade de proteção integral.

\section{REPRESENTATIVIDADE DO PARQUE NACIONAL DO IGUAÇU NO QUADRO DE ÁREAS PROTEGIDAS NO PARANÁ}

A ocupação do Oeste paranaense é relativamente recente (ocorreu de forma mais efetiva a partir da segunda metade do séc. $X X)$ e foi marcada pela atuação de companhias colonizadoras, projetos desenvolvidos pelo Estado e levas de migrantes, motivados pelo contexto político e econômico vigente no país.

A formação de uma frente pioneira de ocupação, materializada pelo deslocamento das fronteiras econômica e demográfica para o interior paranaense, exerceu forte interferência na paisagem. Em poucas décadas, o predomínio de uma paisagem formada por florestas foi substituído por obras de engenharia, núcleos urbanos e expansão da produção agrícola até as barrancas do Rio Paraná, sobretudo a partir de 1940.

Na década de 1940, são colocadas em curso, no Oeste e no Sudoeste [do Paraná], algumas iniciativas oficiais, nas esferas dos governos estadual e federal, conjugadas com uma série de interesses de empresários envolvidos com projetos de colonização e extração de madeira. [...] As empresas colonizadoras privadas tiveram um papel importante no direcionamento e ingerência na forma de integração da Mesorregião Oeste ao sistema produtivo mercantil, não se limitando apenas à venda de terras, mas procurando participar de outros empreendimentos que consideravam lucrativos, como as serrarias (DIAS e CASTELANO, 2015, p. 13). 
Como resultado da incorporação predatória (nas dimensões social e natural) do território paranaense a um sistema produtivo agrícola monocultor, o Paraná apresenta poucas áreas de extensão representativa de floresta remanescente da Mata Atlântica. Conforme mapeamento realizado em 2003, dados disponibilizados demonstram que a cobertura florestal natural do Paraná era de 18\%, e desse número apenas 10\% poderia ser considerado como de florestas bem conservadas (SANQUETTA, 2003).

A situação indicada acima confere grande importância ao Parque Nacional do Iguaçu, localizado no Oeste paranaense (ver Figura 1). Faz parte do conjunto de unidades de conservação de maior destaque no cenário nacional, algo motivado em especial pela especificidade constituída pelas Cataratas do Iguaçu, conjunto de quedas d’àgua que é apresentado como a principal atração para um fluxo de turistas brasileiros e estrangeiros que confere a este parque o título de segundo mais procurado por turistas no Brasil, depois do P.N. da Tijuca, no Rio de Janeiro. Apesar desta porção do PNI (estamos nos referindo às Cataratas do Iguaçu, Figura 2) ser tão divulgada e visitada, o parque em sua totalidade ainda é pouco conhecido e apresenta dificuldades de integração, inclusive com a população que reside em suas proximidades.

Mais do que a expressiva supressão da floresta original no Paraná, ressalta-se o fato de que os ecossistemas naturais remanescentes estão distribuídos de maneira fragmentada. Nesse sentido, a consulta à imagem de satélite dessa parte do Estado permite distinguir nitidamente o contorno do PNI, apresentado na cor vermelha na Figura 3, que se destaca de todo o seu entorno, no lado brasileiro, já tomado por uma agricultura intensiva que se estende até a divisa do parque.

Ao procedermos a uma análise comparativa entre as condições encontradas no entorno do Parque Nacional do Iguaçu, entre 1970 e 2000, identificamos uma ocupação intensa ao longo dessas três décadas, com a população total ampliando-se de 183.103 para 422.419 habitantes. Um crescimento de 130,7\% na área abrangida por esses municípios, que passaram de oito para doze municípios instalados nesse período. Trata-se de um crescimento representativo, cuja dimensão fica mais visível quando comparamos com a média de crescimento no Paraná, no mesmo período, que foi de 38,02\%. É necessário ressaltar, porém, que esse crescimento se deu de maneira concentrada em Foz do Iguaçu, o que torna os números superdimensionados pela sua participação no conjunto (DIAS, 2006).

Como se pode perceber pela imagem exposta pela Figura 3, o território argentino, em sua porção limítrofe ao Brasil, apresenta uma condição mais representativa de conservação de suas florestas, quando comparado com o Oeste-Sudoeste paranaense. Parte dessa área de florestas, localizada na Província de Missiones, está protegida sob os limites do Parque Nacional del Iguazú, que tem como delimitação ao norte o curso inferior do Rio Iguaçu. O 
referido parque argentino conta com 67.620 hectares e forma uma única unidade paisagística com o parque brasileiro.

Figura 1 - Localização do Parque Nacional do Iguaçu - PR

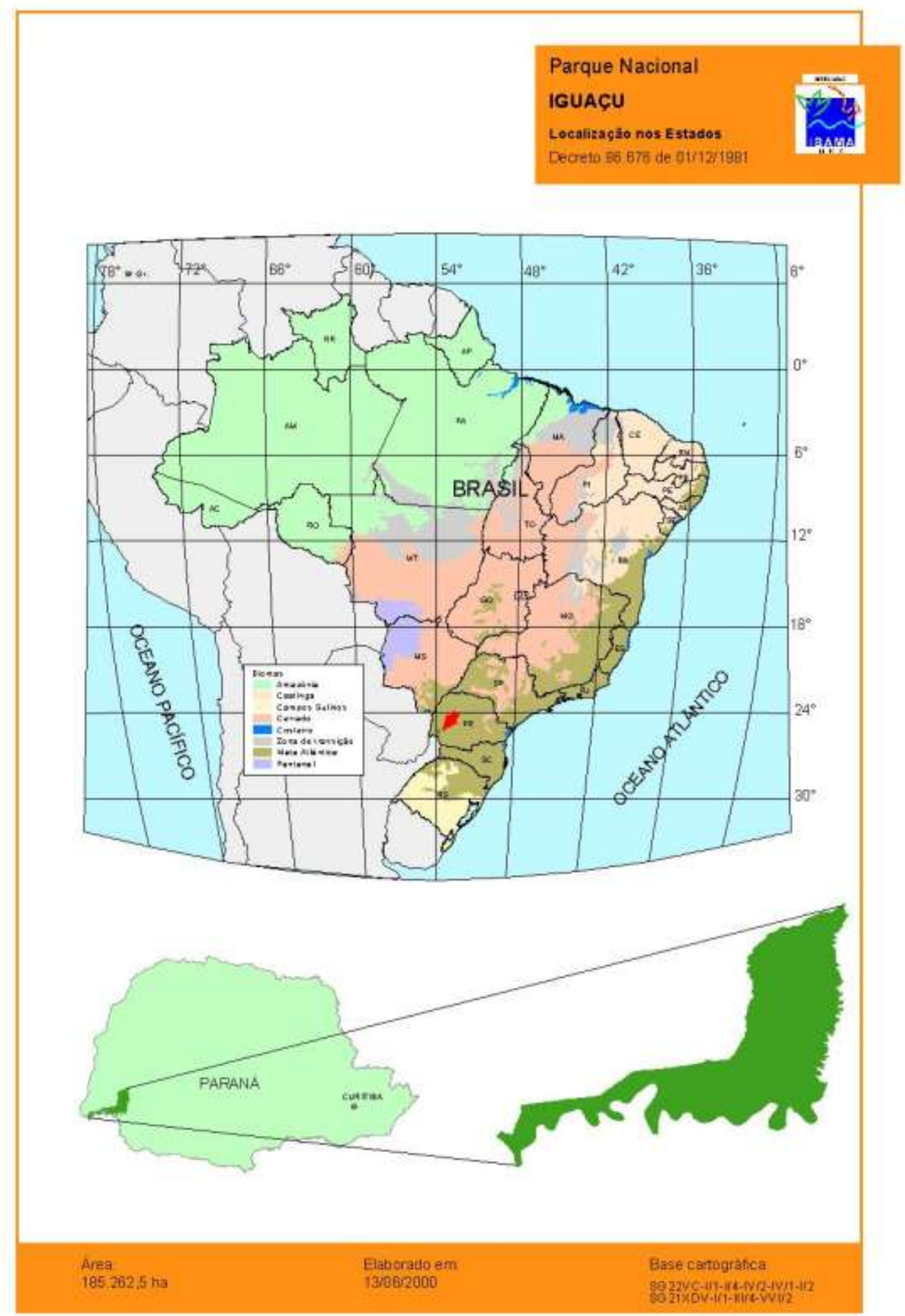

Fonte: IBAMA, 1999. 
Figura 2 - Vista aérea das Cataratas do Iguaçu - divisa entre Brasil e Argentina

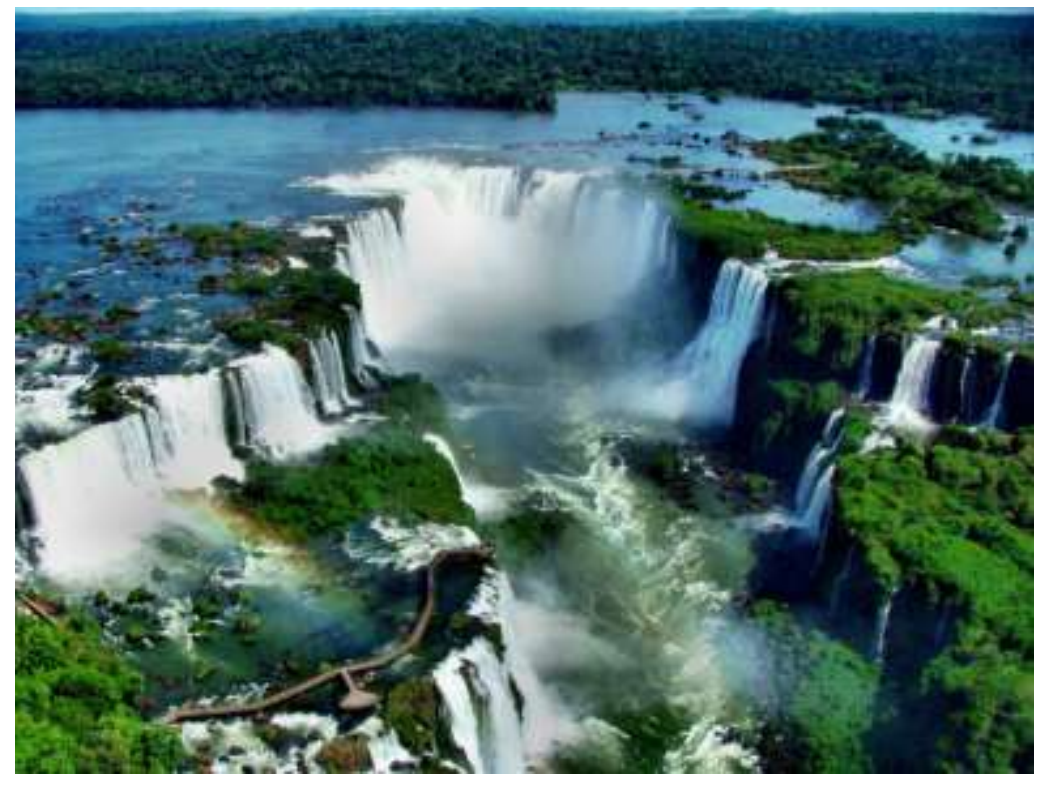

Fonte: Fundação New7Wonders, 2016.

Figura 3 - Imagem de satélite que permite a visualização dos Parques Nacionais do Iguaçu - Brasil (com destaque em vermelho) e del Iguazú - Argentina (na parte meridional, verde)

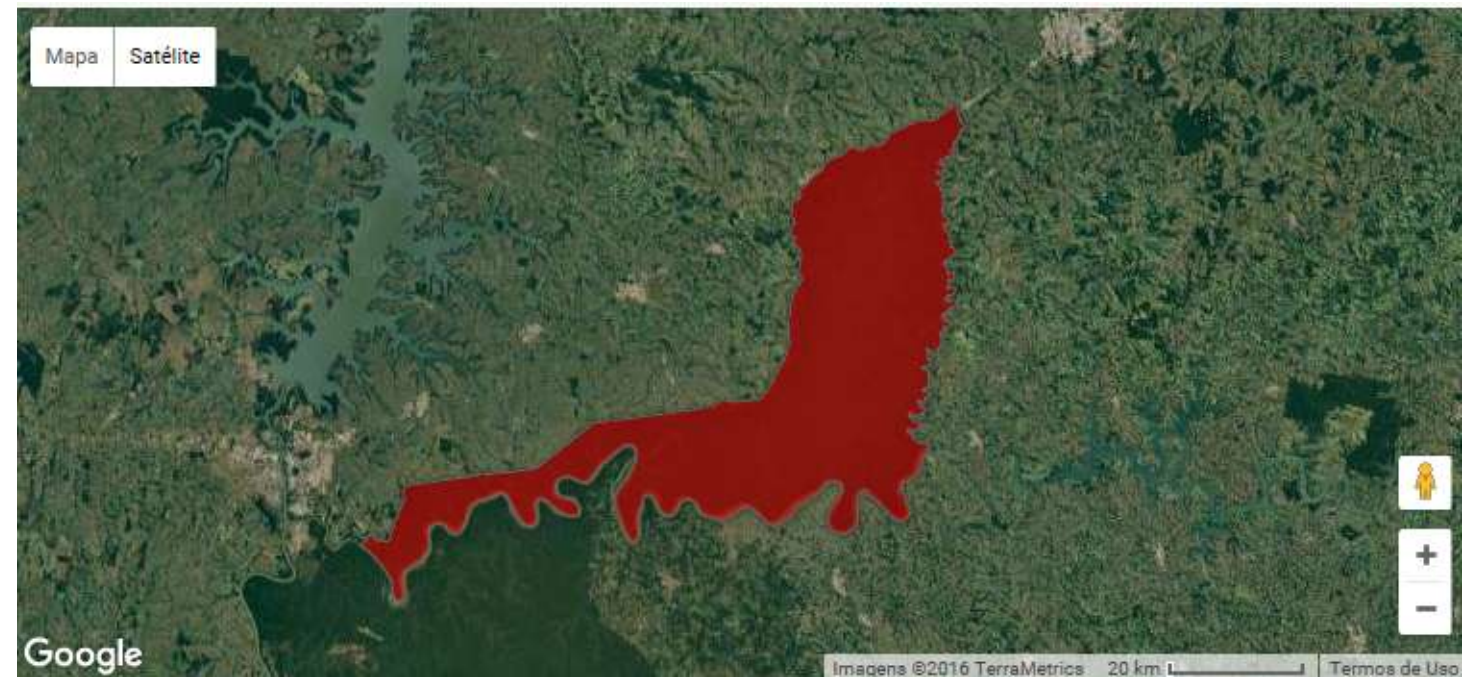

Fonte: Wikiparques, 2016.

A Província de Missiones localiza-se no extremo nordeste do território argentino, tendo como capital a cidade de Posadas. Contando com uma superfície de 29.801 quilômetros quadrados, antes da Guerra da Tríplice Aliança pertencia ao Paraguai. É uma província periférica, longe dos centros industriais e agropecuários da Argentina. Na década de 1970, Missiones tornou-se conhecida como a "Amazônia argentina", devido à distância dos principais centros econômicos e pela grande reserva florestal que possuía, a maior do país (MENDONÇA, 2000). 
Ao contrário do parque brasileiro, o Parque Nacional del Iguazú encontra-se inserido em uma porção do território argentino ainda com alto índice de preservação das condições naturais. Apesar desse parque contar com uma área total que corresponde a pouco mais de um terço do parque brasileiro, além do parque argentino o Norte de Missiones dispõe de outras reservas de proteção ambiental. Entre essas, mencionamos as que se localizam no entorno do Parque Nacional del Iguazú, como o Parque Provincial de Urugua-í (com uma extensão de 84 mil hectares) e diversos parques provinciais e refúgios privados.

É recente a intensificação do processo de ocupação do extremo norte da Província de Missiones, em curso desde a década de 1980. De acordo com Ricobom (2001), a Província de Missiones ainda possui a maior amostra da Floresta Semidecidual em condições de ser preservada, apesar do estímulo à ocupação e colonização da região ao redor do Parque Nacional del Iguazú, causando grande desmatamento, motivado por razões militares e estratégicas desde a década de 1980. Quanto à importância desses dois parques, temos ainda a avaliação de outro autor:

Como individualmente tanto o parque nacional argentino quanto o brasileiro têm área insuficiente para garantir a sua viabilidade a longo prazo e reduzir ao máximo a taxa de extinção de espécies, ambos se beneficiam da sua contigüidade e da existência de maciços florestais que ampliam a área efetivamente protegida além de seus limites e permitem a manutenção de corredores migratórios entre as duas unidades. [...] A colonização da região de Andrezitto na Argentina e a reabertura da estrada do Colono podem comprometer toda a estratégia que está sendo trabalhada por Brasil e Argentina em conjunto para viabilizar a manutenção de um amplo corredor ecológico protegido na área da Selva Paranaense e que, em tese, uniria o Parque Nacional do Iguaçu, ao norte, até o Parque Estadual do Turvo, no oeste do Rio Grande do Sul, atravessando toda a extensão florestada de Missiones. Este projeto arrojado e de difícil consecução já atingiu algumas conquistas muito significativas, com a criação de um Parque Provincial [Parque Provincial do Urugua-í] vizinho ao Parque Nacional del Iguazú que dobra a área protegida do outro lado da fronteira (ROCHA, 1997, p. 15).

O PNI, em território brasileiro, ocupa uma posição de relevo no conjunto de áreas preservadas da Mata Atlântica. Nas palavras de Bigarella (1986, p. 72): "O Parque Nacional do Iguaçu constitui atualmente a única e mais extensa amostra da outrora exuberante floresta do vale do Rio Paraná e de seus afluentes, preservada no país".

Além da importância dos seus atributos qualitativos, pela composição dos seus elementos naturais, o PNI destaca-se pelo seu tamanho representativo (para os padrões de parques do Sul e Sudeste do país), como pode ser verificado pelo Quadro 1, dentro do sistema federal de unidades de conservação existentes no Paraná.

São três as formações florestais encontradas no PNI que se diferenciam conforme as características de altitude e solos, estando inseridas na área de clima subtropical úmido. A parte sul do parque é mais baixa, com altitudes de 200 metros no Rio Iguaçu, sendo essa 
área coberta por Floresta Estacional Semidecídua, que cobre a maior parte da unidade, cujas árvores perdem folhas no inverno. Ao norte, onde as altitudes alcançam mais de 600 metros, temos a Floresta Ombrófila Mista, com araucária, ocupando uma área menor do parque ao longo dos vales dos rios. Acompanhando os rios que cortam o parque, formam-se ainda florestas mais baixas, com oito a 15 metros de altura, onde a riqueza de espécies é menor e as árvores são adaptadas a enchentes periódicas, suportando bem a condição de muita umidade. Esse tipo de vegetação de áreas úmidas, com a predominância de capins, arbustos e árvores baixas, é chamada de Formações Pioneiras de Influência Fluvial (IBAMA, 1999).

Quadro 1 - Parques Nacionais criados no estado do Paraná

\begin{tabular}{|l|r|c|}
\hline PARNA & \multicolumn{1}{|c|}{ Área total } & Diploma Legal de Criação/Ano \\
\hline Iguaçu & 185.262 ha & № $1035 / 1939$ \\
\hline Superagui & $33.860 \mathrm{ha}$ & № 97.688/1989 \\
\hline Ilha Grande & $76.033 \mathrm{ha}$ & Dec. s/no / 1997 \\
\hline Saint-Hilaire/Lange & $25.118 \mathrm{ha}$ & № $10.227 / 2001$ \\
\hline Campos Gerais & $21.298 \mathrm{ha}$ & Dec. s/no / 2006 \\
\hline Guaricana & $49.286 \mathrm{ha}$ & Dec. s/no / 2014 \\
\hline
\end{tabular}

Organizado pelo autor. Fonte: ICMBIO/MMA, 2016.

Este parque abriga grande diversidade de espécies animais, muitas delas vulneráveis ou ameaçadas de extinção. É refúgio da última população viável de onças-pintadas do Sul do país. Foram registradas nessa área aproximadamente 400 espécies de aves e 50 espécies de mamíferos. Há 257 espécies de borboletas registradas, 12 de anfíbios, 41 de serpentes e oito de lagartos (IBAMA, 2004). As informações apresentadas referem-se à fauna contemplada em levantamentos feitos no parque, os quais ainda são incompletos, o que significa que há a possibilidade de a diversidade da fauna encontrada na área ser bem maior.

Quanto à hidrografia, o PNI está situado na bacia hidrográfica do Rio Iguaçu e possui extensa rede de drenagem, constituída por afluentes da margem direita do referido rio, cujas cabeceiras estão à montante da unidade de conservação. Portanto, os rios percorrem trechos de uso do solo distintos, e são afetados no primeiro trecho por atividades como agricultura e esgoto das cidades. Como exceção, temos o Rio Floriano, com bacia hidrográfica de 713 quilômetros quadrados, bacia localizada, quase que em sua integralidade, dentro dos limites do parque. É o único rio do parque que não é diretamente impactado pelo desmatamento, erosão, atividade agrícola ou esgoto doméstico e industrial proveniente das cidades. Essa condição o distingue como referência de monitoramento do ecossistema regional. Já o Rio Iguaçu margeia o parque em toda a sua divisa ao sul. Esse 
rio e os seus afluentes vêm sendo afetados pelas atividades humanas na área do entorno do parque, como, por exemplo, a substituição da vegetação natural por terras cultivadas e a urbanização crescente, dois fatores com grande influência sobre as bacias de drenagem que percorrem o parque.

Também a construção de sucessivas usinas hidrelétricas no Rio Iguaçu em vários trechos, inclusive bem próximo do PNI, como no caso da UHE de Salto Caxias, resultam em interferências na oscilação do nível das águas desse rio (IBAMA, 1999).

No ano de 2013 deu-se início à construção da sexta usina hidrelétrica instalada no Rio Iguaçu, no caso, a U.H. de Baixo Iguaçu, localizada a montante (aproximadamente 500 metros) do PNI e que impacta a zona de amortecimento. A Zona de Transição (ou, conforme a Lei do SNUC, Zona de Amortecimento) do PNI abrange 10 quilômetros de raio a partir dos limites legais circundantes do parque, tendo uma superfície calculada em 2.565 quilômetros quadrados e compreende a área de 13 municípios do Oeste e um do Sudoeste do Paraná.

Outra situação conflitante que envolve o PNI é a busca da reabertura de uma estrada que passa por dentro da área destinada à unidade de conservação. A partir de 1986, com o fechamento da Estrada do Colono (via de 17 quilômetros que atravessava o PNI em sua Zona Intangível, ligando os municípios de Serranópolis do Iguaçu a Capanema) pela Polícia Federal, surgiu um imbróglio - na esfera jurídica, política e econômica - envolvendo a reivindicação pela reabertura da estrada. Essa problemática se estendeu por décadas, com momentos tensos e interesses diversos envolvidos, não sendo possível afirmar que o caso esteja completamente encerrado após a última operação policial que fechou novamente a estrada, no ano de 2001.

\section{IMPLANTAÇÃO E REGULARIZAÇÃO DO PARQUE NACIONAL DO IGUAÇÚ}

$\mathrm{Na}$ conjuntura histórica marcada pelas intensas mudanças que envolviam o país e o Paraná nos anos de 1930, foram estabelecidas ações fundamentais para a implementação, de forma institucionalizada, de uma área de preservação no Oeste paranaense. Em 20 de outubro de 1930 o governo estadual emitiu o Decreto nำ2.153, ampliando a área destinada à futura implantação do parque (que era de 1.008 hectares) para 3.369,90 hectares, suficiente apenas para proteger a porção da floresta mais próxima das Cataratas, e incorporando-a a administração federal.

No Brasil, os parques nacionais são criados através de decretos federais específicos. O primeiro decreto voltado para esse fim foi expedido em 14 de junho de 1937 (Decreto Federal $n^{\circ}$ 1.713), criando o Parque Nacional do Itatiaia, no Rio de Janeiro, o que resultou na primeira unidade de conservação federal destinada à preservação dos patrimônios 
bióticos e fisiográficos do local. Dois anos depois, em 10 de janeiro de 1939, foi criada, no Oeste paranaense, a segunda área de proteção nacional (pelo Decreto Federal oㅜ 1.035), o Parque Nacional do Iguaçu.

A instalação desses parques nacionais ocorreu em sintonia com o contexto de mudanças políticas e econômicas que o país atravessava, a partir da ascensão de Vargas ao poder. Na Constituição de 1934 foi incluído um artigo que definia como responsabilidade da União "proteger belezas naturais e monumentos de valor histórico e artístico". Como consequência, naquele mesmo ano, os principais e inovadores instrumentos relacionados à proteção foram instituídos no país: o Código Florestal, o Código de Águas, o Código de Caça e Pesca e o decreto de proteção aos animais. O Código Florestal criou as condições legais para a formalização do primeiro Parque Nacional no Brasil - o de Itatiaia (RJ), assim como previa a instalação de Florestas Nacionais (MEDEIROS, 2004).

Deve ser considerado ainda que, naquele momento, diversos países já haviam adotado a política de instalação de parques nacionais em seus territórios, inclusive na América do Sul, como a Argentina e o Chile.

Em 1942, representantes da Seção de Parques Nacionais do Serviço Florestal, ligada ao Ministério da Agricultura, encaminharam pedido de ampliação do PNI, propondo que os limites da reserva coincidissem com acidentes naturais do terreno, facilitando a sua delimitação. Conforme o teor da solicitação:

\begin{abstract}
Julgamos oportuno pensar-se desde já em se acrescer a nossa reserva a fim de que não venhamos nos penitenciar quando as despesas forem assustadoras e as matas devastadas [...] Assim, o Parque do Iguassú será compreendido pelos seguintes limites: no Norte, a estrada de Guarapuava; ao Sul, o rio Iguassú; a Oeste, o rio São João e a Este o rio Gonçalves Dias, atingindo assim apreciável área de fácil desapropriação, que na hipótese de não poder ser imediatamente assistida, será conservada, evitando possíveis devastações (SPN-Ministério da Agricultura, 1942 apud IBDF, 1981, p. 911).
\end{abstract}

O pedido de ampliação da área destinada ao parque é aceito e, em 1944, por força de três decretos federais, os seus limites são dilatados para uma delimitação muito próxima da atual. A partir das delimitações aprovadas, as únicas alterações que se deram (estabelecidas pelo Decreto $\mathrm{n}^{\circ} \mathbf{8 6 . 8 7 6}$, de 1ํ de dezembro de 1981) referem-se à exclusão de uma área de aproximadamente 1.400 hectares, onde se encontra a cidade de Santa Tereza do Oeste, no extremo-nordeste do parque e a incorporação de algumas ilhas localizadas ao longo do Rio Iguaçu, no trecho paralelo ao parque.

A ampliação da área destinada ao PNI ocorreu através de decretos federais expedidos em 1944. No entanto, o Estado não providenciou a indenização prevista aos proprietários rurais atingidos por tal medida. Como consequência os mesmos efetuaram a venda 
parcelada das terras, o que resultou na formação de pequenos núcleos de povoamento no interior do PNI, como Santo Alberto, Iguaçulândia e Capoeirinha, entre outros (IBDF, 1981). Essa situação originou usos conflitantes com os objetivos dessa modalidade de unidade de conservação, considerada como de uso indireto, com todas as implicações previstas para esse tipo de unidade.

Somente em 1967 o governo brasileiro deu início aos trabalhos de regularização fundiária na área abrangida pelo parque. Nesse momento de levantamento e regularização, chegou a ser cogitada a proposta de excluir dos domínios do PNI as terras ocupadas pelos agricultores. Tal medida resultaria em seccionar o parque e eliminar de sua área uma faixa de cerca de 20 quilômetros, mas essa proposta não foi aceita.

O levantamento fundiário e a avaliação das benfeitorias foram finalizados em 1972 , constatando-se a existência de 457 famílias residindo no PNI. Dessas famílias, 158 possuíam títulos de propriedade fornecidos pelo governo do Estado do Paraná. As demais famílias eram compostas por ocupantes sem título, arrendatários, parceiros e empregados rurais. A área ocupada por essas propriedades somava 12.000 hectares, dos quais 4.000 eram utilizados para cultivo. Deu-se início à regularização da situação fundiária do parque e, em 1978, o processo de desapropriação permitiu a retirada dos agricultores (IBDF, 1981).

Para viabilizar a transferência das pessoas residentes nas terras sob delimitação do parque, o governo federal desapropriou 12.500 hectares entre os municípios de Foz do Iguaçu e São Miguel do Iguaçu e destinou esta área para o reassentamento das famílias removidas. A área destinada deu origem ao que o INCRA denominou de Projeto Integrado de Colonização Ocoí - PIC Ocoí.

Mas, se a situação encontrava-se resolvida para os representantes do $\mathrm{PNI}$, o mesmo não se pode dizer sobre as famílias retiradas, pois parte das famílias reassentadas foram novamente obrigadas a se deslocar. Conforme Vencatto (2010, p. 22 e 23):

[...] depois da construção da Usina Hidrelétrica de Itaipu, com a formação do lago, a área [PIC OCOÍ] foi reduzida para 4.500 ha situados apenas no município de São Miguel do Iguaçu. [...] novas desapropriações vividas pelos recém reassentados, a partir da construção da Usina Hidrelétrica de Itaipu na década de 1980, constituindo mais um processo compulsório de migração em menos de 10 anos.

No interior do parque, ainda ficou pendente a situação das fazendas "Maggi" e "Salinet". Por serem classificadas como "empresas rurais", não puderam ser expropriadas por interesse social, sendo expropriáveis através do instrumento legal de utilidade pública.

Em 1980, um decreto federal declarou de utilidade pública as áreas das empresas rurais existentes no parque e permitiu a sua desapropriação. Ao final do processo de regularização, não permaneceu nenhuma propriedade privada no interior da unidade de 
conservação. As famílias foram retiradas da área do PNI e realocadas em municípios próximos que se encontram sob o marco legal que trata da área denominada de Faixa de Fronteira (faixa de 150 quilômetros de largura, paralela à linha divisória terrestre do território nacional). Essa particularidade resultou em uma condição de insegurança jurídica aos proprietários reassentados e somente a partir do ano de 2014 os títulos de propriedade começaram a ser regularizados definitivamente. Conforme informação divulgada pelo INCRA (2014), a regularização foi iniciada pela Instrução Normativa $n^{\circ}$ 80, de 13 de maio de 2014, que permitiu ao INCRA regularizar imóveis rurais com áreas de até 100 hectares, fora da Amazônia Legal, localizados em área compreendida pela Faixa de Fronteira.

As áreas anteriormente cultivadas no interior do parque foram deixadas sem intervenção, para que houvesse a regeneração natural da floresta. Atualmente não há remanescentes de construções das antigas propriedades e as áreas anteriormente ocupadas estão parcialmente recuperadas pela vegetação, existindo apenas alguns vestígios de pastagens que ainda podem ser visualizados por imagens de satélite.

\section{CONSIDERAÇÕES FINAIS}

A formalização, no plano jurídico-institucional, de uma unidade de conservação representa uma etapa necessária, mas mostra-se insuficiente para oferecer as garantias para a sua manutenção e para que cumpra os objetivos propostos para a sua criação.

Quando levantamos a situação do conjunto das unidades de conservação do país, percebemos que o PNI realmente se apresenta em uma situação mais vantajosa. De acordo com informações contidas no plano de manejo mais recente, o PNI tem a sua situação fundiária praticamente regularizada, com pendências pontuais como é o caso de algumas pequenas ilhas (desabitadas) localizadas no Rio Iguaçu, no trecho compreendido pelo parque.

O fato de o PNI possuir sua delimitação regularizada, estar com a situação fundiária resolvida, não contar com moradores em seu interior, ser visitado por centenas de milhares de turistas e possuir o título de Patrimônio Natural da Humanidade, propicia uma condição favorável aos objetivos legais e de manejo previstos para essa unidade de conservação. Tanto assim que este parque torna-se uma espécie de modelo de unidade de conservação bem-sucedida, sob esses aspectos, frequentemente indicada por ambientalistas e funcionários de órgãos públicos ambientais.

Os aspectos positivos associados a essa unidade de conservação não significam a inexistência de problemas graves a serem resolvidos ou, ao menos, amenizados, que também afetam outras áreas protegidas, como a caça ilegal, conflitos de uso com a 
população do entorno (em especial nas propriedades localizadas na Zona de Amortecimento) e a reivindicação pela reabertura da Estrada do Colono, entre outros.

Torna-se necessário um plano de ação e investimento, por parte do Estado, assim como a cooperação e envolvimento da população que habita as cercanias do parque. Acontece que identificamos a existência de dificuldades para essas pessoas se sentirem motivadas a contribuir, de forma ativa, com a preservação da unidade. Até porque iniciativas por parte do IBAMA, do ICMBio e da direção do Parque que procuram envolver as comunidades vizinhas ao PNI, nos diversos municípios abrangidos pela unidade, só vieram a ocorrer após a operação policial que fechou à força a Estrada do Colono, em 2001. Até então, as ações estavam voltadas exclusivamente para Foz do Iguaçu, com exceção da fiscalização.

Conforme a nossa avaliação, a relação entre as instituições responsáveis pelo parque e a população vizinha a ele foi marcada pela falta de iniciativas visando a integração e o conflito envolvendo a Estrada do Colono impôs-se como força motivadora para repensar essa relação.

É preciso ressaltar que o processo de retirada e reassentamento das famílias que residiam no interior do PNI perdurou entre o final dos anos 1960 até o final dos anos 1970, e não ocorreu sem a resistência inicial por parte dos agricultores. Também, não deve ser menosprezado o contexto político vigente à época, em plena ditadura militar, que não permitia contestações de qualquer tipo (frequentemente acusadas de subversão) ou margem para o diálogo e negociação com o Estado.

Esse contexto favorável a criar situações conflituosas - constituição de áreas protegidas que resultam no deslocamento de famílias residentes em seu interior - é que torna possível entender porque o processo de regularização fundiária de maneira completa de uma unidade de conservação, geralmente, enfrenta alguns percalços e se dá a longo prazo. Mesmo resolvida a situação da regularização fundiária da unidade de conservação sempre restarão outras questões em aberto para reflexão e encaminhamentos práticos. Por essa razão torna-se importante a formação - de fato - de um conselho consultivo ou deliberativo (conforme previsto no regulamento do SNUC, Art. 17 - Decreto no 4.340/ ago. 2002) que garanta a participação de representantes da população do entorno, para opinar sobre os assuntos de interesse geral para além do núcleo administrativo do parque.

\section{REFERÊNCIAS}

BIGARELLA, João J. Lutas e frustrações ecológicas- um desafio. Curitiba: ADEA Associação de Defesa e Educação Ambiental, 1986. 
BRASIL. Lei № 9.985, de 18 de julho de 2000. Institui O Sistema Nacional de Unidades de Conservação da Natureza.

Decreto № 4.340, de 22 de agosto de 2002. Regulamenta artigos da Lei ํo 9.985, de 18 de julho de 2000, que dispõe sobre o SNUC.

DIAS, Edson dos S.; CASTELANO, Maria J. O processo de formação social do espaço de fronteira do Oeste-Sudoeste Paranaense. Revista Geografia, Ensino \& Pesquisa. Santa Maria (RS): UFSM, vol. 19, no1, p. 7-26, jan./abr. 2015. Disponível em: < https://periodicos.ufsm.br/geografia/article/view/14908/pdf_1 > Acesso em: 21 abr. 2016.

Desenvolvimento regional e conservação ambiental: análise de um conflito socioambiental envolvendo o Parque Nacional do Iguaçu - PR. 2006. Tese (Doutorado em Geografia), UNESP, P. Prudente.

FERREIRA, Lúcia da C. Dimensões humanas da biodiversidade: mudanças sociais e conflitos em torno de áreas protegidas no Vale do Ribeira, SP, Brasil. In: Ambiente \& Sociedade. Campinas (SP): UNICAMP/Nepam - Núcleo de Estudos e Pesquisas Ambientais, Vol. VII, no 1, p. 45-66, jan./jun. 2004.

FUNDAÇÃO New7Wonders. Disponível em: <https://visit7wonders.com/br/cataratas-doiguacu/ > Acesso em: 15 ago. 2016.

GODOY, Larissa R.C.; LEUZINGER, Márcia D. O financiamento o sistema nacional de unidades de conservação no Brasil: características e tendências. Revista de Informação Legislativa. Brasília: Senado Federal, Ano 52, nํ206, p. 223-243, abr./jun. 2015. Disponível em:

<http://www2.senado.leg.br/bdsf/bitstream/handle/id/512457/001041600.pdf?sequence=1 > Acesso em: 14 abr. 2016.

GONCHOROSKY, Julio. Administração de unidades de conservação. In: 1ํ SIMPÓSIO DE ÁREAS PROTEGIDAS, 2001, Pelotas (RS). Anais... Pelotas: Universidade Católica de Pelotas, 2 a 4 out. 2001, CD, p. 56-61.

IBAMA - Instituto Brasileiro do Meio Ambiente e dos Recursos Naturais Renováveis. Cobrança de compensação ambiental beneficia 130 parques e reservas federais, estaduais e municipais. Brasília, 7 jul. 2005. Disponível em: <www.ibama.gov.br> Acesso em: 18 abr. 2016.

Plano de Manejo do Parque Nacional do Iguaçu. Brasília, 1999. Disponível em: <http://www2.ibama.gov.br/unidades/parques/planos_de_manejo/17/html/index.htm>. Acesso em: 18 abr. 2016.

Parque Nacional do Iguaçu: Plano de Ação Emergencial. Brasília: PNMA; GTZ; KfW, abr. 1994. (mimeo).

IBDF - Instituto Brasileiro de Desenvolvimento Florestal. Plano de Manejo - Parque Nacional do Iguaçu. Brasília: IBDF, 1981.

ICMBIO - Instituto Chico Mendes de Conservação da Biodiversidade. Parque Nacional de Itatiaia tem 51\% de área regularizada. Notícias, 10/06/2016.Disponível em: < http://www.icmbio.gov.br/portal/ultimas-noticias/20-geral/7972-parque-nacional-de-itatiaiaatinge-51-de-area-regularizada> Acesso em: 15 ago. 2016. 
.MMA - Disponível em: <http://www.icmbio.gov.br/portal/parna-do-iguacu?

highlight=WyJpZ3VhXHUwMGU3dSJd> Acesso em: 21 set. 2016.

INCRA - Instituto Nacional de Colonização e Reforma Agrária. Incra entrega títulos e inicia regularização fundiária em Faixa de Fronteira. Notícias. 20/10/2014.Disponível em: < http://www.incra.gov.br/ noticias/incra-entrega-titulos-e-inicia-regularizacao-fundiaria-emfaixa-de-fronteira > Acesso em: 15 ago. 2016.

MEDEIROS, Rodrigo; YOUNG, Carlos E. F. (Eds.). Contribuição das unidades de conservação brasileiras para a economia nacional: relatório final. Brasília: UNEP/WCMC, 2011. Disponível em:

http://www.mma.gov.br/estruturas/240/_arquivos/relatorio_final_contribuio_uc_para_a_econ omia_nacional_reduzido_240.pdf. Acesso em: 06 ago. 2016.

A política de criação de áreas protegidas no Brasil: evolução, contradições e conflitos. In: IV CONGRESSO BRASILEIRO DE UNIDADES DE CONSERVAÇÃO, 2004, Curitiba (PR). Anais... Curitiba: Fundação O Boticário de Proteção à Natureza: Rede Nacional Pró-Unidades de Conservação, Vol. I, 2004. p. 601-611.

MEDEIROS, João de D.; SAVI, Maurício. Unidades de Conservação na Floresta Ombrófila Mista: a distância entre o desejável e o possível. In: 56 CONGRESSO NACIONAL DE BOTÂNICA, 2005, Curitiba (PR). Anais... Curitiba: SBB - Sociedade Botânica do Brasil, 2005. p. 01 - 10. Disponível em: <http://www.botanica.org.br/buscar-trabalhos-

cientificos.php?evento=

$56 \mathrm{CNBot} \&$ titulo=\&area_conhecimento=todos\&autores $=\&$ palavras $=\&$ result $\_$por_pagi $=5 \&$ Busc ar..$=17 \&$ Buscar. $y=14>$ Acesso em: 12 dez. 2017.

MENDONÇA, Luciana de A. Parques Nacionais do Iguaçu e Iguazú: uma fronteira ambientalista entre Brasil e Argentina. XXII REUNIÃO BRASILEIRA DE ANTROPOLOGIA, Anais... Brasília (DF), jul. 2000. p. $65-80$.

MILLER, Kenton R. Evolução do conceito de áreas de proteção - oportunidades para o século XXI. In: CONGRESSO BRASILEIRO DE UNIDADES DE CONSERVAÇÃO (1997: Curitiba). Anais... Curitiba: UFPR; IBAMA; MMA; UICN, 1997. p. 3 - 21.

PÁDUA, Maria T. J. Sistema brasileiro de unidades de conservação: de onde viemos e para onde vamos? I CONGRESSO BRASILEIRO DE UNIDADES DE CONSERVAÇÃO, 1997, Curitiba (PR). Anais... Curitiba: Instituto Ambiental do Paraná : Universidade Livre do Meio Ambiente : Rede Nacional Pró-Unidades de Conservação, Vol. I, 1997. p. 214-236.

RICOBOM, Arnaldo E. O Parque do Iguaçu como unidade de conservação da natureza no âmbito do Mercosul: os problemas decorrentes da degradação ambiental. 2001.

Dissertação (Mestrado em Geografia), UFPR, Curitiba. Disponível em: < http://acervodigital.ufpr.br/bitstream/handle/1884/8899/O\%20PARQUE\%20DO\%20IGUA\%c3 \%87U\%20COMO\%20UNIDADE\%20DE\%20CONSERVA\%c3\%87\%c3\%830\%20DA\%20NA TUREZA\%20NO\%20\%c3\%82MBITO\%20DO\%20MERCOSUL\%200S\%20PROBLEMAS\%2 ODEC.pdf?sequence=1\&isAllowed=y > Acesso em: 10 abr. 2016.

ROCHA, Sérgio Brant. A “Estrada do Colono” e o Parque Nacional do Iguaçu. Brasília: IBAMA, 1997. (mimeo).

SANQUETTA, Carlos R. Os números atuais da cobertura florestal do Paraná. Curitiba: UFPR, 2003. 
VENCATTO, Rudy N. "Mas com isso a gente começou duas vezes no meio do mato": memórias dos desapropriados do Parque Nacional do Iguaçu (Oeste do Paraná, 1970 2009). Mal. C. Rondon, (Dissertação de Mestrado em História), UNIOESTE, 2010.

WIKIPARQUES. Disponível em:

<http://www.wikiparques.org/wiki/Parque_Nacional_do_lgua\%C3\%A7u> Acesso em: 15 ago. 2016.

WWF - World Wide Fund for Nature - Brasil. Políticas Públicas 2017. Cortes no orçamento da União atingem Unidades de Conservação e combate ao desmatamento. Disponível em: < https://d3nehc6yl9qzo4.cloudfront.net/downloads/ploa_mma_definitivo_baixa.pdf> Acesso em: 20 dez. 2017.

Recebido: agosto de 2017. Aceito: janeiro de 2018. 